studies of climate models forced with continually increasing greenhouse gas concentrations.

The author reduces the uncertainty of climate science mostly to the fundamental problem of nonlinear dynamics and the related problem of determining accurate initial conditions. Other fundamental aspects are neglected, such as the climate system's phase space with infinitely many degrees of freedom, the openness of the system and the need to impose various semi-empirical parameters on climate models. As a result, the book comes across as over-optimistic about the task of analysing and modelling the climate system and its sensitivity.

As to the science of global warming, the author takes this to mean the purely physical sciences, exploring myriad processes that take place in the atmosphere, the oceans, the lithosphere and so on. Thus a planetaryscale view of global warming emerges, with relocated deserts, rising sea level, a defunct Gulf Stream and more El Niño events. What these changes mean for humankind is not specified. Instead, the author stays vague, mentioning the "considerable inconvenience over the next few decades for our particular species" and issuing general warnings about forthcoming unspecified "dangers".

The science of global warming should, however, also deal with the specifics of these dangers: that is, it should look at the possibility of abating and adapting to them. And as ecosystems and people experience global warming mostly locally, this analysis must be done on the local scale.

The author mentions Thomas Malthus's prediction, 200 years ago, that England was heading towards "gigantic inevitable famine" because of the steady increase in population. Perhaps we should learn from Malthus's science that the fate of the environment and humankind is only partly determined by natural dynamics, such as population growth and the carbon cycle, and that social dynamics and technological innovations are important as well.

Every scenario of possible future climate change is based on scenarios about the anthropogenic output of greenhouse gases: that is, on the outcome of a highly complex social system. The challenge of climate science therefore is to integrate the social sciences - by coupling economics models, diagnosing the socio-scientific construction of the 'climate problem' or analysing the impact of climate policy on people's wellbeing. Unfortunately, the author has chosen not to take up this challenge; and where he refers to old misconceptions, such as the infamous "climate and civilisation" hypothesis of Huntington, he fails to put them in proper perspective.

Hans von Storch is at the Institute of Hydrophysics, GKSS Research Center, PO Box, 21502 Geesthacht, Germany.

\section{Thumbs up for signal work}

\section{The Expression of the Emotions in Man and Animals}

by Charles Darwin

Third edition, with introduction, afterword and commentaries by Paul Ekman. HarperCollins/Oxford University Press: 1998. Pp. 473. £16.99, \$30

\section{Simon Baron-Cohen}

Almost everyone has heard of Darwin's The Origin of Species, and many will have heard of his book The Descent of Man. These books disseminated the theory that now stands as the framework for the biological sciences. But his book The Expression of the Emotions in Man and Animals is less well known, except possibly among readers in the field of psychology. This book is where Darwin laid out his highly original thesis that emotional expressions in humans have their counterparts in the behaviour of other species, suggesting an evolved commonality of form and function.

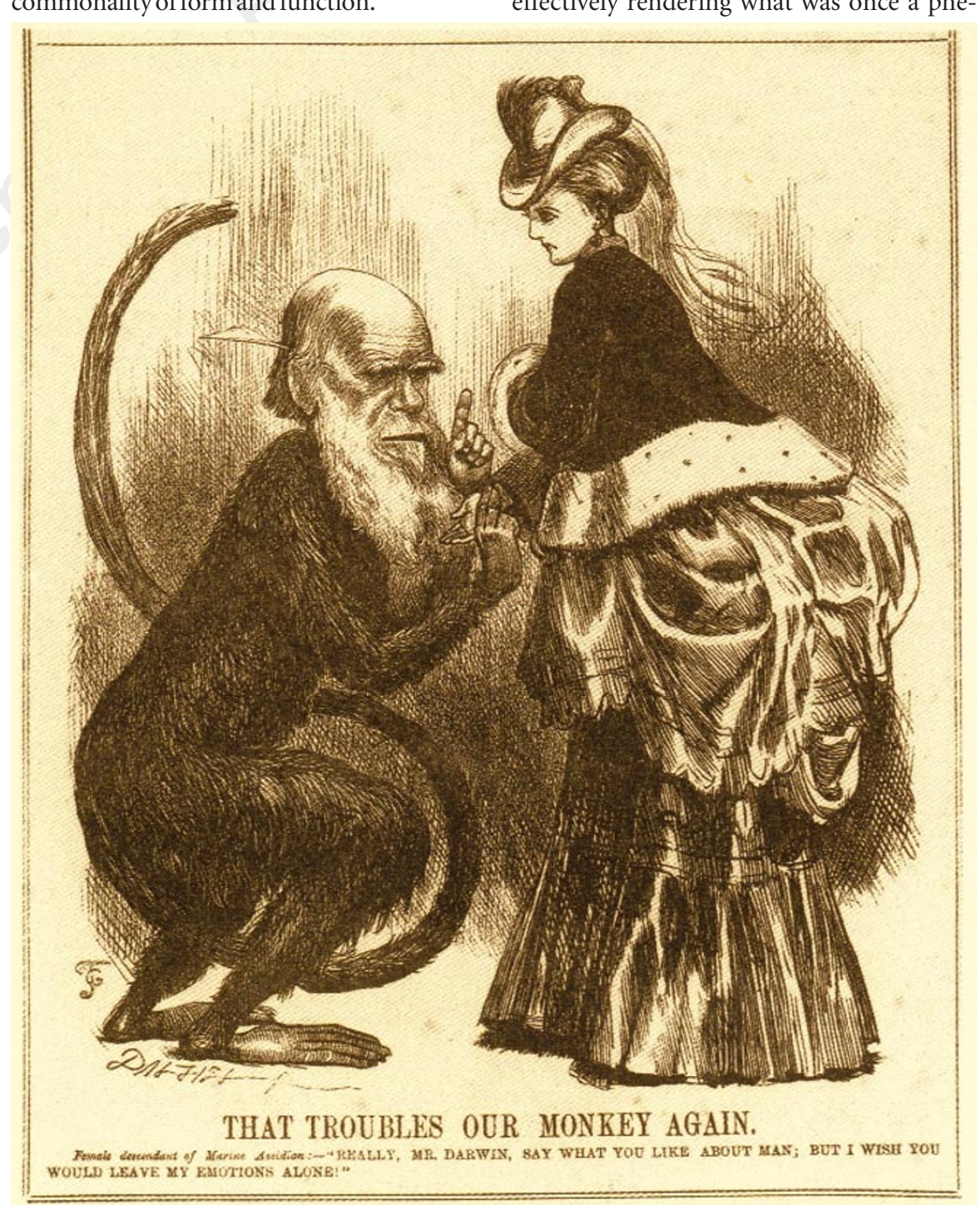

Seconding that emotion: she may not have liked it, but Ekman's findings back up Darwin's work.

The first edition came out in 1872 and sold 9,000 copies in the first four months. The text contains a wealth of detail from a wide range of primate species, describing the expression of fear, anger, contentment and sadness. It relates these to observations of the behaviour of human infants. Some of the observations were drawn directly from his descriptions of his own child: for example, where he details the expression of guilt on his son's face when the boy was just two years old.

The second edition of the book was edited by Darwin's son Francis, and appeared in 1889 , seven years after Charles Darwin died. Francis appears to have brought it out because Charles had prepared many revisions and additional material not available in the first edition.

Now, more than a century later, the world's leading Darwin scholar on the subject of the emotions, Paul Ekman, has produced a treasure trove of a third edition. Ekman is widely known in this field for his empirical contribution to defining the musculature of facial expressions of emotion, effectively rendering what was once a phe- 
nomenon characterized only by subjective description (and thus difficult to study scientifically) into a branch of physiology where objective measurement could be practised.

Ekman's own work has not been confined simply to validating the muscular changes in emotion, although this has been a major advance in the field. He has also studied both recognition and expression of emotion in every aspect, but perhaps most famously in cross-cultural studies. His finding that a core set of emotions are universal, irrespective of culture, is of course a result perfectly predicted from the Darwinian theory.

It might amuse readers to hear that Ekman set out to study emotional recognition in faraway tribes in non-literate parts of the world just to prove Darwin wrong. As the results turned out, Ekman's a priori cultural determinist view was refuted, Darwin's biological determinist view was upheld, and the results steered Ekman into a career that generated an enormous wealth of new data in this field.

Ekman has produced this third edition so as to bring Darwin's book into contact with this new data. Darwin's ideas were mostly based on anecdote, correspondence, some observation and speculation. Many of these ideas have been confirmed by later work, and Ekman's editorial commentary throughout the text helps the reader to sort out which of these have stood the test of time, and which Darwin simply got wrong. To ensure they are balanced, commentaries are also based on correspondence from a distinguished panel of international researchers working on emotion.

This new text is scholarship at its best. The strength of Darwin's writing still shines through, as well as his drive to explain the form of each emotional expression: why is blushing associated with embarrassment? Why do we purse our lips when we concentrate? But Darwin's own account is now properly set in the contemporary scientific context. The commentaries appear in boxes within the text, producing the effect of a dialogue between Darwin and modern science, bridging the century.

The publishers immodestly include a subtitle on the front cover that reads "Definitive Edition". This is a fair description as we leave the twentieth century, although it might be seen as a touch myopic by reviewers of future editions. Time will tell. But without doubt, this new book will be required reading for Darwin scholars of emotion. $\quad \square$ Simon Baron-Cohen is in the Department of Experimental Psychology, University of Cambridge, Downing Street, Cambridge CB2 3EB, UK.

\section{Related book}

A new paperback edition of Charles Lyell's Principles of Geology has just been published (Penguin, £9.99). Darwin constantly referred to this work while voyaging on The Beagle. It has now been edited into a single volume by the historian of science James Secord, who also provides an introduction outlining Lyell's writing strategy and an explanation of the book's enormous cultural impact. A bibliography of reviews is also included.

\section{A feastfor the senses}

Tibaldo and the Hole in the Calendar by Abner Shimony

Copernicus: 1998. Pp. 165. \$21, £15.50

\section{Stephen Battersby}

Tibaldo Bondi lives in Bologna, Italy, in the late sixteenth century. In 1582 (the year is significant), we find him at the age of 11 studying at the school of St-Joseph-in-the-Corner, hoping one day to become a great doctor. $\mathrm{He}$ is very intelligent and very sensible; a little too good, perhaps. But one day in a Latin dictation he translates a proclamation from the Pope that horrifies him: Gregory XIII has decided to replace the Julian calendar, whose imprecision means that calendar holidays are gradually slipping from their proper season, with a better one concocted by a commission of astronomers.

This is sensible, and satisfies Tibaldo. But, to make up the difference in time accumulated over one-and-a-half millennia, there will be no 15-25 October that year - there will be a hole in the calendar, and Tibaldo's twelfth birthday will fall through it. He becomes obsessed, and sets out with great resourcefulness to fight the calendar and get his birthday back.

This is a lovely book. It is an Improving Tale for children, but not excessively moralistic; it is written in an austere style, but one that allows for some dry humour. And it is beautifully produced, with a cover and illustrations drawn in stylized Renaissance cartoon fashion by the author's son, Jonathan Shimony. They, too, are often playful, and worth lingering over.

On the whole it is also an adult book Abner Shimony writes about the power of propaganda and the details of childbirth, and he doesn't avoid using difficult words where they are needed. The aim is unashamedly to teach, but the story allows the author to do this naturally: the problem of constructing a consistent calendar leads us to astronomy, especially the astronomy of the late Renaissance. Tibaldo's studies lead us to the medical science of the time; and his quest takes us into the politics.

In every case, we are shown the virtues of common sense. At a time when the natural philosophers of Europe were beginning to appreciate the power of experiment and

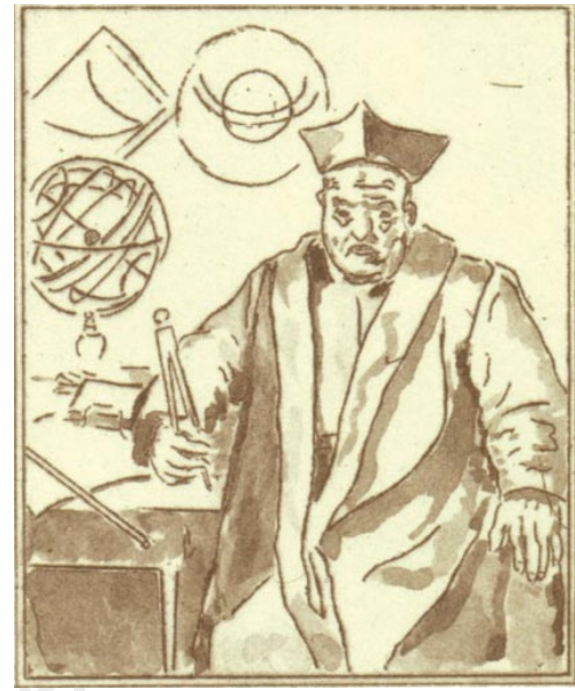

observation, many of Shimony's ordinary people already have a practical sense that can almost be equated with empirical science.

We see this in the early description of Tibaldo's father, Lorenzo, at work. Once the distinguished professor of medicine, Turisanus, has given his pompous and meaningless diagnosis (which Shimony describes ironically as "the most important part of the treatment”), Lorenzo sets about helping the patient. He cleans and dresses wounds, or sets bones - the things that he and his predecessors have learned from experience. More explicitly, Tibaldo's older sister Anna Maria, a midwife, advises him "to observe which treatments work, and which do not". Tibaldo is very lucky to be surrounded by such a sensible family, disdainful of superstition, and benefiting from a few centuries of authorial hindsight. Yet somehow the result isn't implausible.

But what about the story? Does Tibaldo succeed in his quest, repair the hole in the calendar and enjoy his birthday feast after all? Or must he grow up and abandon his obsession? I'm not telling. Read it.

Stephen Battersby is an assistant editor at Nature.

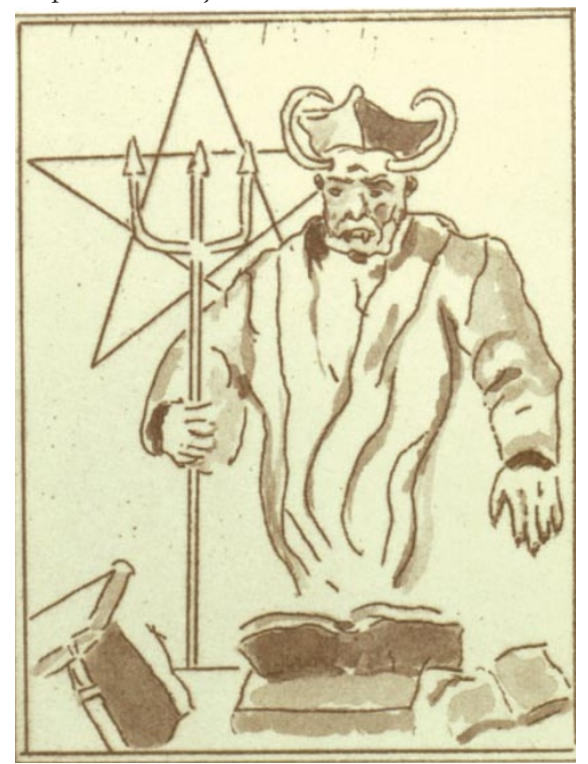

